\title{
ANALISIS KADAR KALSIUM OKSIDA (CaO) PADA BATU KARANG DI DAERAH PESISIR BAYANG DAMPELAS DONGGALA
}

\section{Annisa Dian Islamiyati dan Paulus Hengky Abram}

\author{
Jurusan Pendidikan MIPA \\ Fakultas Keguruan dan IImu Pendidikan Universitas Tadulako Palu
}

\begin{abstract}
Coral reefs are classified as coral or coral limestone. These corals contain of a high level of calcium purity with more than $90 \%$. These clacium are in the from calcite $\left(\mathrm{CaCO}_{3}\right)$. Calcite can be used in the industrial sector wich can be processed into a catalyst and use as a mixture of portland cement.its economic value increases by converting $\mathrm{CaCO}_{3}$ to $\mathrm{CaO}$ trough the calcination process at high temperatures. The coral sampels were taken from the coastal area of Bayang, Dampelas Donggala wich consisted of 2 samples. i.e coastal and montain coral reefs. The CaO levevls contained in coral reefs wer determined by qualitative and quantitative analysis method using XRF (X-Ray Fluorescence). XRF result showed that were $\mathrm{CaO}$ compounds in each coral reef sample. The $\mathrm{CaO}$ level in the coastal reef was $92,08 \%$ before calcination and $92,11 \%$ after calcination. Whereas the CaO level in te mountain coastal reef was $94,51 \%$ before calcination and $96,77 \%$ after calcination.
\end{abstract}

Keywords: Coral, calcination, calcium oxide, xrf (x-ray fluorescence)

\section{PEMBAHASAN}

Keberadaan sumber daya alam dimuka bumi ini sangat berlimpah, potensi tersebut meliputi minyak, gas, dan bahan-bahan mineral (Ukhtiyani dkk., 2017). Sumber daya mineral merupakan sumber daya yang telah disediakan oleh kulit bumi sebagai bagian dari mineral batuan dalam jumlah tertentu. Sumber daya ini bila diolah dapat menghasilkan logam dan berbagai bahan keperluan proses industri sebagai penunjang kehidupan manusia (Sari, 2016).

Salah satu mineral pada batuan yang berpotensi untuk dikembangkan adalah Kalsium Oksida yang di peroleh dari hasil kalsinasi Kalsium karbonat $\left(\mathrm{CaCO}_{3}\right)$ pada suhu tinggi (Noviyanti dkk., 2015). Mineral dibagi dalam kelompok-kelompok menurut unsur-unsur yang menyusunnya. Komposisi kimia yang terdapat pada batu diantaranya $\mathrm{FeCO}_{3}, \mathrm{PbCO}_{3}, \mathrm{ZnCO}_{3}, \mathrm{Cu}_{2}(\mathrm{OH})_{2} \mathrm{CO}$, $\mathrm{SiO}_{2}, \mathrm{Al}_{2} \mathrm{O}_{3}$, dan $\mathrm{CaCO}_{3}$ (Pambudi \& Suprapto, 2018).

Batu merupakan suatu zat padat, keras, dan tahan lama. Karakteristik dari beberapa jenis batu bervariasi bergantung pada kondisi dan cara pembentukannya. Salah satu jenis batuan adalah batu karang yang memiliki komposisi utama mineral aragonit $\left(\mathrm{CaCO}_{3}\right)$, mineral aragonit bersifat metastabil sehingga dapat menyebabkan terjadinya perubahan atau diagenesa menjadi bentuk lain yang lebih stabil (Erlangga dkk., 2016).

Kalsit $\left(\mathrm{CaCO}_{3}\right)$ merupakan fase yang paling stabil dan banyak digunakan dalam bidang industri, kesehatan, dan pertanian. Kandungan kalsium karbonat ini dapat diubah menjadi kalsium oksida dengan cara kalsinasi sehingga lebih mudah dimurnikan untuk mendapatkan kalsiumnya (Noviyanti dkk., 2015). Dengan cara ini batu karang dapat dimanfaatkan dalam sektor Industri sebagai katalis heterogen dan sebagai bahan campuran semen portland (Suhardin dkk., 2018).
Mineral tersebut mempunyai nilai ekonomis yang tinggi karena dapat diperoleh dalam jumlah yang banyak (Ali dkk., 2019). Untuk mendapatkan kalsium oksida tersebut perlu dilakukan kalsinasi terlebih dahulu agar $\mathrm{CaO}$ yang diperoleh mempunyai kemurnian yang tinggi sehingga mampu berperan sebagai katalis (Oko \& Feri, 2019).

Kalsium oksida adalah senyawa industri yang sangat penting, dapat digunakan sebagai katalis, zat pembersih limbah beracun, bahan campuran cat dan juga pemanfaatan lainnya (Roy \& Bhattacharya, 2011). Salah satu keuggulan dari katalis $\mathrm{CaO}$ adalah berbentuk padat sehingga mudah dipisahkan pada akhir reaksi. Sedangkan kelemahan dari katalis ini salah satunya adalah mudah bereaksi dengan udara yang mengandung air membentuk $\mathrm{Ca}(\mathrm{OH})_{2}$ sehingga menyebabkan penurunan aktivasi kataliknya (Kesic dkk., 2016).

Kawasan batu karang yang berada di Kabupaten Donggala Khususnya kecamatan dampelas secara geografis terletak antara $0^{\circ} 25^{\prime} 08^{\prime \prime}-0^{\circ} 05^{\prime} 27^{\prime \prime}$ LS dan $119^{\circ} 46^{\prime} 16^{\prime \prime}-120^{\circ} 06^{\prime} 03^{\prime \prime}$ BT (BPS, 2017). Kawasan batu karang ini banyak terdapat di Desa Bayang Kecamatan Dampelas. Masyarakat di desa tersebut memanfaatkan batu karang tersebut sebagai bahan untuk konstruksi bangunan rumah masyarakat.

Ketersediaan bahan baku yang cukup melimpah serta dilihat dari unsur-unsur yang terkandung didalamnya, kalsit yang terdapat pada batu karang dapat diubah menjadi $\mathrm{CaO}$ dan diolah menjadi katalis heterogen dalam bidang industri untuk meningkatkan nilai ekonomis batuan (Suhardin dkk., 2018). CaO dapat diperoleh melalui dekomposisi kalsit atau $\mathrm{CaCO}_{3}$ pada suhu yang tinggi (Lesbani dkk., 2015).

Salah satu metode yang dapat digunakan untuk menganalisis kandungan kalsium oksida dan mineral-mineral lainnya yaitu dengan menggunakan X-Ray-Fluorescence (XRF) 
(Balasubramanian \& Muthukumaraswamy, 2016). Metode XRF merupakan tekhnik analisis secara kualitatif dan kuaintitatif. Analisis kualitatif memberikan informasi pada unsur atau senayawa yang terkandung dalam bahan, analisis kuantitatif memberikan informasi megenai jumlah unsur yang terkandung dalam bahan (Fitri dkk., 2016).

Berdasarkan uraian tersebut, maka peneliti tertarik untuk menggunakan X-Ray Fluorescence (XRF) untuk mengidentifikasi dan menentukan kadar $\mathrm{CaO}$ pada batu karang desa Bayang kecamatan Dampelas, kabupaten Donggala.

\section{METODE}

Alat yang digunakan pada penelitian ini yaitu palu/martil, oven, gegep, neraca analitik, desikator, ayakan 70 mesh, gelas kimia $250 \mathrm{ml}$, lumpang dan alu, cawan porselin, cawan krusibel, tanur/muffle furnance, serta seperangkat alat XRF. Sedangkan bahan yang digunakan pada penelitian ini yaitu batu karang dan aquades.

\section{Pengambilan sampel}

Sampel batuan diambil dari daerah pesisir pantai desa Bayang di dua lokasi yaitu batuan yang berada di pinggiran pantai dan batuan yang berada di pegunungan. Pengambilan sampel batuan di lapangan dengan cara grab sampling, yaitu mengambil bongkah batuan di lokasi (Wijaya dkk., 2016).

Batuan yang diambil merupakan batu karang yang masuk pada golongan batu gamping terumbu atau batu gamping koral yang berwarna putih dan umumnya pejal, biasanya sebagian sudah membentuk perbukitan, sedang sebagian lainnya berkembang terus di bawah (Permana \& Eraku, 2017).

Pengambilan sampel dilakukan di Desa Bayang Kecamatan Dampelas Kabupaten Donggala yaitu batu karang yang berada di pantai dan batu karang yang berada di gunung. Seperti pada Gambar 1 berikut:

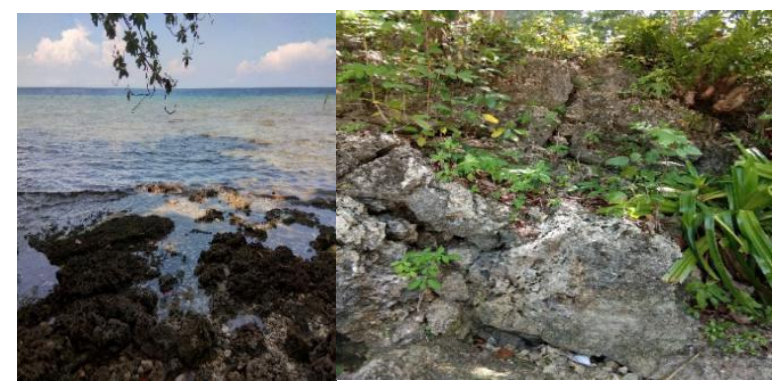

Gambar 1. Lokasi pengambilan sampel

\section{Preparasi sampel batuan}

Sampel batuan yang diambil dibersihkan dari material-material lain yang menempel menggunakan aquades panas. Lalu sampel di keringkan di bawah sinar matahari selama 3 jam (Ardiansyah dkk., 2015). Kemudian sampel di tumbuk hingga halus menggunakan lumpang dan alu, selanjutnya sampel diayak dengan menggunakan ayakan 70 mesh (Suhardin dkk., 2018).

\section{Analisis kadar air}

Cawan porselin kosong dipanaskan dalam oven pada suhu $110^{\circ} \mathrm{C}$ selama 1 jam, didinginkan di dalam desikator selama 15 menit, kemudian ditimbang sebagai $W_{3}$. Sampel yang lolos ayakan 70 mesh ditimbang sebanyak 10 gram masukkan ke dalam cawan, timbang massanya $\left(W_{1}\right)$, kemudian dikeringkan di dalam oven pada suhu $110^{\circ} \mathrm{C}$ selama 2 jam, setelah itu didinginkan dalam desikator selama 5 menit dan ditimbang menggunakan neraca analitik sebagai $W_{2}$. Prosedur Ini dilakukan berulang-ulang sampai diperoleh berat konstan. Kemudian ditentukan kadar airnya dengan rumus sebagai berikut (BSN, 2008):

$$
\mathrm{w}=\frac{\mathrm{W}_{1}-\mathrm{W}_{2}}{\mathrm{~W}_{2}-\mathrm{W}_{3}} \times 100 \%
$$

dengan:

$$
\begin{array}{ll}
\text { w } & \text { : Kadar air (\%) } \\
\text { W1 } & \text { : Berat cawan dan batu basah (gram) } \\
\text { W2 } & \text { : Berat cawan dan batu kering (gram) } \\
\text { W3 } & \text { : Berat cawan (gram) } \\
\text { (W1 }- \text { W2): Berat air } \\
\text { (W2 -W3): berat batu kering (gram) }
\end{array}
$$

\section{Analisis kadar abu}

Cawan krusibel kosong ditimbang terlebih dahulu $\left(m_{1}\right)$, sampel yang lolos ayakan menggunakan ayakan 70 mesh ditimbang sebanyak 10 gram dan dimasukkan ke dalam cawan krusibel yang telah dikethaui massanya $\left(m_{2}\right)$, kemudian sampel dikalsinasi menggunakan mesin tanur pada suhu $900^{\circ} \mathrm{C}$ selama 1 jam. Setelah itu didinginkan dalam desikator lalu ditimbang kembali menggunakan neraca analitik $\left(m_{3}\right)$ Kemudian dihitung kadar abu sampel dengan menggunakan persamaan (BSN, 2010):

$$
m=\frac{m 3-m 1}{m 2-m 1} \times 100 \%
$$

\section{Dengan:}

m : Kadar abu (\%) 


\section{$\mathrm{m}_{1} \quad$ : Berat cawan kosong (gram) \\ $\mathrm{m}_{2} \quad$ : Berat cawan + sampel contoh (gram) \\ $\mathrm{m}_{3} \quad$ : Berat cawan + abu (gram) \\ Analisis kadar $\mathrm{CaO}$}

Sampel batuan hasil kalsinasi dianalisis menggunakan instrumen XRF yang bertujuan untuk mengidentifikasi jenis dan menentukan kadar $\mathrm{CaO}$ yang terkandung di dalam sampel menggunakan radiasi sinar- $X$ yang diserap dan dipantulkan oleh sampel (Alimin dkk., 2016).

\section{HASIL DAN PEMBAHASAN Pengambilan dan preparasi sampel}

Sampel batu karang diambil dengan menggunakan metode grab sampling yaitu pengambilan batuan dalam bentuk bongkahan di lokasi (Wijaya dkk., 2016). Sampel batuan diambi di daerah pesisir pantai desa Bayang kecamatan Dampelas kabupaten Donggala. Titik pengambilan sampel berada di dua tempat yaitu batuan yang berada di pinggiran pantai dan batuan yang berada di gunung yang berdekatan dengan pantai. Sampel batuan yang diambil memiliki ciri-ciri berwarna putih, dan memiliki pori,berbentuk massif (Utami dkk., 2016).

\section{Kadar air}

Metode analisis kadar air terbagi dalam beberapa cara diantaranya adalah metode pengeringan atau pengovenan, metode destilasi, metode kimiawi, dan metode gravimetri (Sir dkk., 2016). Analisis kadar air sampel batuan bertujuan untuk menyatakan hubungan antara fase udara, air dan butiran padat yang berada dalam volume sampel. Kadar air pada batuan menunjukkan perbandingan berat air yang mengisi rongga pori material batuan terhadap berat partikel padatnya. (BSN, 2008).

Kadar air yang diperoleh yaitu pada sampel batu karang gunung (sampel $\mathrm{A}$ ) sebesar 0,31\%, $0,40 \%$, dan $0,40 \%$ sehingga diperoleh kadar air rata-rata sebesar $0,37 \%$. Pada sampel batu karang pantai (sampel B) sebesar 0,246\%, $0,275 \%$, dan $0,275 \%$ sehingga diperoleh kadar air rata-rata sebesar $0,265 \%$.

\section{Kadar abu}

Analisis kadar abu suatu sampel perlu ditentukan untuk melakukan estimasi mineral yang terkandung dalam sampel. Abu pada batuan merupakan bahan anorganik yang terbentuk karena proses pembakaran(Pamekas dkk., 2019). Analisis kadar abu pada batuan bertujuan untuk mengetahui sifat-sifatdan kualitasnya (BSN, 2010).

Terjadi perubahan warna pada sampel yaitu sampel batu karang gunung berwarna kuning keabuan (Sampel A) sedangkan sampel batu karang pantai (sampel B) berwarna Putih keruh. Hal ini disebabkan karena sampel telah mengalami oksidasi dan proses pengabuan ini merupakan proses langsung yaitu sampel dioksidasi pada suhu tinggi sehingga zat yang tertinggal setelah pembakaran ditimbang (Sunartaty \& Yulia, 2017).

Kadar abu yang diperoleh yaitu pada sampel batu karang gunung (sampel A) sebesar 70,26\%, dan pada sampel batu karang Pantai (sampel B) sebesar $71,89 \%$.

\section{Analisis kadar kalsium oksida (CaO)}

Setelah proses kalsinasi selesai, sampel dianalisis menggunakan XRF (X-Ray Fluorescence) untuk mengetahui persentase $\mathrm{CaO}$ pada sampel (Suhardin dkk., 2018).

Metode X-Ray Fluorescence digunakan untuk menganalisa unsur penyusun suatu bahan dengan adanya radiasi sinar- $X$ yag diserap dan dipantulkan oleh target atau sampel. Metode ini paling banyak digunakan untuk menganalisis bahan-bahan geologi seperti batuan, mineral dan sedimen (Sari, 2016). Penggunaan metode $X$-Ray Fluorescence karena tekhnik ini mempunyai satuan part per million (ppm) (Jamaluddin \& Umar, 2018).

Unsur dapat ditentukan keberadaannya secara langsung tanpa ada ketetapan standar untuk melakukan analisis. Hasil keseluruhan dari karakterisasi sampel tersebut berupa data secara kualitatif dan kuantitatif (Li dkk., 2017). Hasil analisis XRF menunjukkan komposisi batu karang tersusun atas beberapa senyawa dengan persentase yang berbeda-beda. Tabel 1 menunjukkan kandungan senyawa oksida pada sampel batu karang gunung (sampel A) sebelum dan setelah kalsinasi. Tabel 2 menunjukkan komposisi senyawa oksida batu karang pantai (sampel B) sebelum dan setelah kalsinasi.

Tabel 1. Komposisi batu karang gunung (sampel A) sebelum dan setelah kalsinasi dalam bentuk oksida

\begin{tabular}{cccc}
\hline \multirow{2}{*}{ No } & \multirow{2}{*}{ Oksida } & \multicolumn{2}{c}{ Persentase (\%) } \\
\cline { 3 - 4 } 1. & $\mathrm{CaO}$ & Sebelum kalsinasi & Setelah kalsinasi \\
\hline 2. & $\mathrm{SiO}_{2}$ & 92,08 & 92,11 \\
\hline 3. & $\mathrm{Fe}_{2} \mathrm{O}_{3}$ & 6,34 & 5,99 \\
\hline 4. & $\mathrm{SrO}$ & 1,02 & 1,16 \\
\hline 5. & $\mathrm{Nb}_{2} \mathrm{O}_{5}$ & 0,526 & 0,589 \\
\hline 6. & $\mathrm{In}_{2} \mathrm{O}_{3}$ & 0,0187 & 0,281 \\
\hline 7 & $\mathrm{SnO}_{2}$ & 0,0093 & 0,0070 \\
\hline 8. & $\mathrm{Sb}_{2} \mathrm{O}_{3}$ & 0,0077 & 0,0068 \\
\hline & & 0,0061 & 0,0093 \\
\hline
\end{tabular}


Tabel 2. Komposisi batu karang pantai (sampel B) sebelum dan sesudah kalsinasi dalam bentuk oksida

\begin{tabular}{|c|c|c|c|}
\hline \multirow{2}{*}{ No } & \multirow{2}{*}{ Oksida } & \multicolumn{2}{|c|}{ Persentase (\%) } \\
\hline & & Sebelum kalsinasi & Setelah kalsinasi \\
\hline 1. & $\mathrm{CaO}$ & 94,51 & 96,77 \\
\hline 2. & $\mathrm{SiO}_{2}$ & 2,83 & - \\
\hline 3. & $\mathrm{SrO}$ & 2,30 & 2,92 \\
\hline 4. & $\mathrm{Fe}_{2} \mathrm{O}_{3}$ & 0,252 & 0,0183 \\
\hline 5. & $\mathrm{Nb}_{2} \mathrm{O}_{5}$ & 0,374 & 0,0264 \\
\hline 6. & $\mathrm{MoO}_{3}$ & 0,275 & 0,0174 \\
\hline 7. & $\mathrm{RuO}_{4}$ & 0,0139 & 0,0093 \\
\hline 8. & $\mathrm{Sb}_{2} \mathrm{O}_{3}$ & 0,0115 & 0,0093 \\
\hline 9. & $\mathrm{SnO}_{2}$ & 0,0105 & 0,0089 \\
\hline 10. & $\ln _{2} \mathrm{O}_{3}$ & 0,0099 & 0,0080 \\
\hline
\end{tabular}

Hasil pengukuran pada Tabel 1 dan 2 menujukkan bahwa batu karang tersusun atas beberapa kandungan senyawa terbanyak yaitu kalsium oksida. Persentase $\mathrm{CaO}$ pada batu karang gunung (sampel A ) 92,08\% sebelum kalsinasi dan $92,11 \%$ seteah kalsinasi. Pada batu karang pantai persentase kandungan $\mathrm{CaO}$ lebih besar dari pada sampel B yaitu sebesar $94,51 \%$ sebelum kalsinasi dan $96,77 \%$ setelah kalsinasi.

Perbandingan spesifik mengenai kandungan kalsium oksida pada sampel batu karang gunung (sampel A) dan sampel batu karang pantai (sampel B) dapat dilihat pada tabel 3 berikut:

Tabel 3. Perbandingan kadar $\mathrm{CaO}$ pada sampel A dan sampel $\mathrm{B}$

\begin{tabular}{cccc}
\hline No & \multicolumn{2}{c}{ Sampel } & \multicolumn{2}{c}{ Persentase kandungan CaO (\%) } \\
\cline { 3 - 4 } & & Sebelum Kalsinasi & Setelah Kalsinasi \\
\hline 1 & Batu Karang Gunung (sampel A) & 92,08 & 92,11 \\
\hline 2 & Batu karang pantai (sampel B) & 94,51 & 96,77 \\
\hline
\end{tabular}

Terdapat perbedaan yang signifikan pada kandungan $\mathrm{CaO}$ yang diperoleh pada masingmasing sampel dimana persentase kandungan $\mathrm{CaO}$ pada sampel A sebelum kalsinasi sebesar $92,08 \%$ dan meningkat sebesar $0,03 \%$ setelah kalsinasi yaitu sebesar 92,11\%. Sementara pada sampel $\mathrm{B}$, persentase kandungan $\mathrm{CaO}$ yang diperoleh sebesar $94,51 \%$ sebelum kalsinasi dan meningkat sebesar 2,26\% yaitu sebesar 96,77\%.

Kandungan $\mathrm{CaO}$ pada batu karang pantai lebih tinggi dibandingkan batu karang gunung, hal ini disebabkan karena batu karang gunung (sampel
A) telah mengalami proses sedimentasi sehingga unsur senyawa kimia yang masih murni telah berubah. Sedangkan pada batu karang pantai (sampel B) tumbuh secara insitu sehingga unsur senyawa kimia masih murni dan belum berubah (Santika \& Mulyadi, 2017).

Kadar $\mathrm{CaO}$ pada batuan berasal dari butiran batu yang terdiri dari fragmen organisme seperti foraminifera, algae, moluska, koral dan sebagainya (Hidayatillah dkk., 2020). Perbandingan persentase kandungan $\mathrm{CaO}$ pada batu karang dapat dilihat pada Gambar 2 berikut:

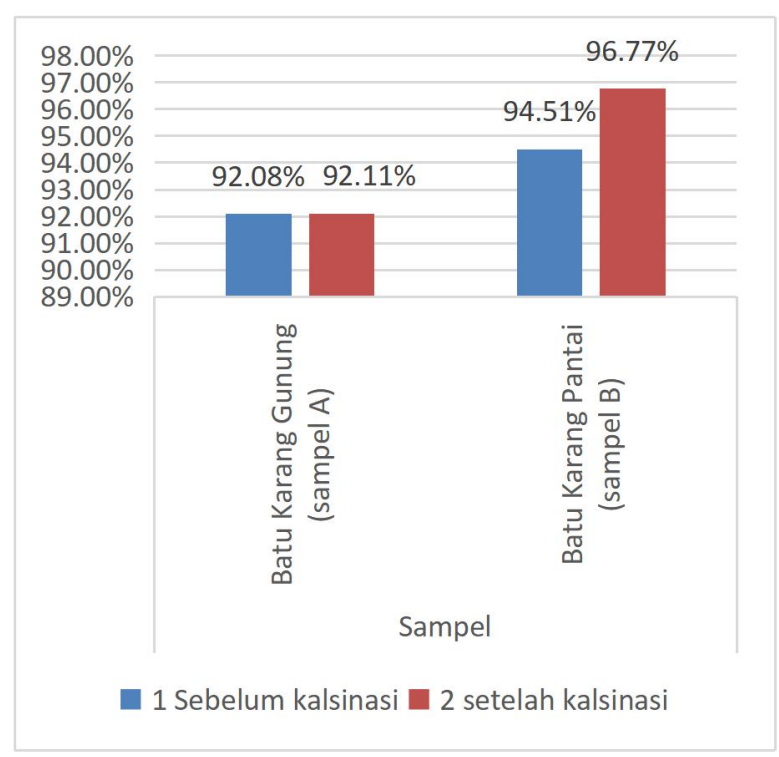




\section{Gambar 2. Grafik persentase kandungan $\mathrm{CaO}$}

Gambar 2 memperlihatkan kandungan kalsium oksida yang tinggi yaitu lebih dari $90 \%$ menunjukkan bahwa penyusun utama batu karang adalah mineral kalsium oksida. Tingginya kandungan kalsium menunjukkan bahwa batu tersebut merupaakan batuan dengan tingkat kemurnian yang tinggi (Suhardin dkk., 2018).

Tingginya kadar $\mathrm{CaO}$ dan rendahnya kadar senyawa oksida lainnya seperti $\mathrm{SiO}_{2}, \mathrm{SrO}, \mathrm{Fe}_{2} \mathrm{O}_{3}$ dan SrO menunjukkan bahwa batu karang merupakan jenis batuan yang lebih ekonomis dan diinterpretasikan karena memiliki persentase butir lebih banyak dibadingkan matriksnya (Hidayatillah dkk., 2020).

\section{KESIMPULAN}

Kadar $\mathrm{CaO}$ yang diperoleh pada sampel batu karang gunung adalah sebesar $92,08 \%$ sebelum kalsinasi dan 92,12\% setelah kalsinasi. Pada sampel batu karang pantai kadar $\mathrm{CaO}$ yang diperoleh sebesar $94,51 \%$ sebelum kalsinasi dan $96,77 \%$ setelah kalinasi.

\section{UCAPAN TERIMA KASIH}

Penulis mengucapkan terima kasih kepada Bapak Paulus Hengky Abram yang telah memberikan banyak masukan dan saran untuk tulisan ini. Dan juga kepada pihak-pihak yang telah banyak membantu, khususnya kepala laboratorium, laboran laboraturium Kimia FKIP Universitas Tadulako. dan laboratorium sains XRD dan XRF Universitas Hasanuddin telah memberikan kesempatan kepada penulis untuk melakukan penelitian sehingga penelitian ini berjalan dengan lancar.

\section{DAFTAR PUSTAKA}

Ali, R. K., Qadaryati, N., \& Widadi, S. (2019). Analisis kualitas untuk optimasi pemanfaatan potensi sumber daya mineral non logam dan batuan di kecamatan Lumbir, kabupaten Bayumas. Jurnal Teknik, 40(3), 161-168.

Alimin, Maryono, \& Putri, S. E. (2016). Analisis kandungan mineral pasir pantai Losari kota Makassar menggunakan XRF dan XRD. Jurnal Chemica, 17(2), 19-23.

Ardiansyah, M., Farida, M., \& Irfan, U. R. (2015). Studi provenance batu pasir formasi walanae daerah Lalebata kecamatan Lamuru kabupaten Bone provinsi Sulawesi Selatan. Geosains, 11(01), 13-18.

Balasubramanian, G., \& Muthukumaraswamy, S. A. (2016). On the empirical study of elemental analysis and metal testing using XRF spectrum analysis algorithm. Internastional Journal of Engineering and Applied Scciences, 3(1), 61-67.

BPS. (2017). Kecamatan Dampelas dalam angka 2017.

BSN. (2008). Cara uji penentuan kadar air untuk
Kualitas $\mathrm{CaO}$ yang diperoleh dipengaruhi oleh salah satu faktor yaitu oleh proses pemanasan atau proses kalsinasi. Semakin tinggi suhu kalsinasi suatu sampel maka kualitas $\mathrm{CaO}$ semakin bagus dan dapat dimanfaatkan dalam bidang industri sebagai katalis heterogen (Haryono dkk., 2018). Dan bila dilihat dari kadar $\mathrm{CaO}$ yang diperoleh batu karang dapat juga dimanfaatkan sebagai bahan campuran semen. Menurut Nurwaskito (2015) semakin banyak jumlah kadar $\mathrm{CaO}$ yang terdapat pada batu gamping maka semakin baik untuk digunakan pada bahan pembuatan semen. Dalam hal ini batu karang masuk dalam golongan batu gamping terumbu atau batu gamping koral (Permana \& Eraku, 2017). tanah dan batuan di laboratorium.

BSN. (2010). Analisis kadar abu contoh batubara. Erlangga, B. D., Mulyadi, D., \& Cahyarini, S. Y. (2016). Analisis petrografi dan X-Ray Diffraction untuk deteksi kalsit non destruktif dari fosil karang porites endapan terumbu kuarter Kendari, Sulawesi Tenggara. Jurnal RISET Geologi dan Pertambangan, 26(1), 15.

Fitri, N., Yusibani, E., \& Yufita, E. (2016). Identifikasi kandungan material perekat pada benteng purba di kawasan Aceh Besar menggunakan XRF. Journal of Aceh Physics Sociesty, 5(2), 14-18.

Haryono, Natanael, L. C., Rukiah, \& Yulianti, Y. B (2018). Kalsium oksida mikropartikel dari cangkang telur sebagai katalis pada sintesis biodiesel dari minyak goreng bekas. Jurnal Material dan Energi Indonesia, 08(01), 8-15.

Hidayatillah, A. S., Winarno, T., \& Khasanah, R. (2020). Hubungan antara fasies batugamping terhadap kualitasnya sebagai bahan baku semen portland menurut kadar $\mathrm{CaO}$ dan senyawa terkait di kuari $\mathrm{B}$ dan $\mathrm{C}$, PT Indocement Tunggal Prakarsa Tbk Unit Palimanan, Cirebon. Jurnal Geosains dan Teknologi, 3(1), 1.

Jamaluddin, \& Umar, E. P. (2018). Identifikasi kandungan unsur logam batuan menggunakan metode XRF (X-Ray Fluorescence) (studi kasus: kabupaten Buton). Jurnal Geocelebes, 2(2), 47-52.

Kesic, Z., Lukic, I., Zdujic, M., Mojovic, L., \& Skala D. (2016). Calcium oxide based catalyst for biodiesel production: a review. Chemical Industry and Chemical Engineering Quarterly, 22(4), 391-408.

Lesbani, A., Susi, Y., Verawaty, M., \& Mohadi, R. (2015). Calcium oxide decomposed from chicken's and goat's bones as catalyst for converting discarded cooking oil to be biodiesel. Aceh International Journal of Science and Technology, 4(1), 7-13.

Li, F., Lu, A., \& Wang, J. (2017). Modeling of chromium, copper, zinc, arsenic and lead using portable X-Ray Fluorescence 
spectrometer based on discrete wavelet transform. International Journal of Environmental Research and Public Health, 14(1163), 1-11.

Noviyanti, Jasruddin, \& Sujiono, E. H. (2015). Karakterisasi kalsium karbonat $\left(\mathrm{Ca}\left(\mathrm{CO}_{3}\right)\right)$ dari batu kapur kelurahan Tellu Limpoe kecamatan Suppa. Jurnal Sains dan Pendidikan Fisika, 11(2), 169-172.

Nurwaskito, A. (2015). Analisis kualitas batugamping sebagai bahan baku utama semen portland pada PT. Semen Tonasa Provinsi Sulawesi Selatan. Jurnal Geomine,

dan kadar abu daerah Bentarsari, kecamatan Salem, kabupaten Brebes, provinsi Jawa Tengah. Padjadjaran Geoscience Journal, 3 , 281-286.

Permana, A. P., \& Eraku, S. S. (2017). Analisis stratigrafi daerah Tanjung Kramat kecamatan Hulonthalangi kota Gorontalo. Jurnal Geomine, 5(1).

Roy, A., \& Bhattacharya, J. (2011). Microwaveassisted synthesis and characterization of $\mathrm{CaO}$ nanoparticles. International Journal of Nanoscience, 10(3), 413-418.

Santika, A. W., \& Mulyadi, D. (2017). Geokimia batugamping daerah Montong, Tuban, Jawa Timur. Jurnal RISET Geologi dan Pertambangan, 27(2), 227-238.

Sari, R. K. (2016). Potensi mineral batuan tambang bukit 12 dengan metode $X R D$, XRF, dan AAS. Jurnal EKSAKTA, 12, 13-23.

Sir, T., Udiana, I., \& Isu, S. (2016). Perbandingan pengukuran kadar air tanah lempung menggunakan metode gravimetry dan metode gypsum block berdasarkan variasi kedalaman. Jurnal Teknik Sipil, 5(2), 213226.

Suhardin, A., Ulum, M. S., \& Darwis, D. (2018). Penentuan komposisi serta suhu kalsinasi optimum $\mathrm{CaO}$ dari batu kapur kecamatan
2(1).

Oko, S., \& Feri, M. (2019). Pengembangan katalis $\mathrm{CaO}$ dari cangkang telur ayam dengan impregnasi $\mathrm{KOH}$ dan aplikasinya terhadap pembuatan biodiesel dari minyak jarak. Jurnal Teknologi, 11(2), 103-110.

Pambudi, M. A. R., \& Suprapto. (2018). Penentuan kadar tembaga (Cu) dalam sampel batuan mineral. Jurnal Sains Dan Seni ITS, 7(2), 20-23.

Pamekas, F., Satrio, Reza, M. G. G., \& Nurdrajat. (2019). Kerangka sekuen pengendapan batubara berdasarkan analisis nilai sulfur

Banawa. Journal of Science and Technology, 7(1), 30-35.

Sunartaty, R., \& Yulia, R. (2017). Pembuatan abu dan karakteristik kadar air dan kadar abu dari abu pelepah kelapa. Seminar Nasional Kemaritiman Aceh, 1, 560-562.

Ukhtiyani, I., Darwis, D., \& Iqbal, I. (2017). Purifikasi dan karakterisasi silika $\left(\mathrm{SiO}_{2}\right)$ berbasis pasir kuarsa dari desa Pasir Putih kecamatan Pamona Selatan Kabupaten Poso. Natural Science: Journal of Science and Technology, 6(3), 270-275.

Utami, E. D., Raharja, R. D., Anggara, F., \& Harijoko, A. (2016). Mineralogi dan geokimia intrusi di tambang batubara Bukit Asam, Sumatera Selatan, Indonesia. Proceeding, Seminar Hasil Kebumian Ke-9 Peran Penelitian IImu Kebumian Dalam Pembberdayaan Masyarakat.

Wijaya, I. P. K., Lestari, W., Ariyanti, N., Pandu, J., Sifuddin, F., Utama, W., \& Bahri, A. S. (2016). Studi kelayakan perangkap $\mathrm{CO}_{2}$ berdasarkan analisa fisik sedimen (studi kasus: formasi kabuh, cekungan Jawa Timur Utara). Converence on Inovation and Industrial Applications (CINIA), 227-231. 